best kind. " Recently the Wolfson Research Laboratories have invited all general practitioners with desktop instruments for measuring plasma cholesterol concentration to participate in a national quality assessment programme ${ }^{12}$; local biochemistry or haematology laboratories will be in a good position to provide advice about other schemes and back up services.

Desktop microanalysers have come of age, but the far reaching consequences of their uncontrolled use have not been fully grasped by the early adopters of this new technology. If a new technology is really essential in modern primary health care it must be introduced in a patient centred way that researches the risks, benefits, and opportunity costs so that what the government calls "customers" can at least know that their doctors are striving for an informed professional view of what is in their best interests and applying it responsibly. Internal and external quality control of biomedical assays and the risks of cross infection from other diagnostic equipment are important issues for general practitioners and primary care nursing staff today.

Professor of General Practice,

N C H STOTT

University of Wales College of Medicine,

Cardiff CF3 7PN

1 Neville RG. Introduction of new diagnostic aids in general practice. Update 1988;36:2311-5.

2 National Cholesterol Education Program. Report of the expert panel on detection, evaluation and treatment of high blood cholesterol in adults. Arch Intern Med 1988;148:36-9.

3 Shaper AG, Pocock SJ. Risk factors for ischaemic heart disease in British men. British Health fournal 1987;57:11-6.

4 Smith WCS, Kenicer MB, Maryon-Davies A, Evans AE, Yarnell J. Blood cholesterol: is population screening warranted in the UK? Lancet 1989;i:372-3.

Broughton PMG, Bullock DG, Cramb R. Quality in plasma cholesterol measurements in primary care. Br Med F 1989;298:297-8.

6 Petranje G, Petranje M, Scobie IN, et al. Quality control of home monitoring of blood glucose concentrations. BrMed f 1984;288:757.

7 Holloran SP. Experience with Reflolux 11/BM 1-44 glycerine stick blood glucose meter system. Ann Clin Biochem 1987;24:168-9.

8 Rady AA, Jones KW, Holloran SP, Marks V. Bedside blood glucose measurement: quality control and assessment. Ann Clin Biochem 1987;24(suppl 1):170-1.

and assessment. Ann Clin Biochem 1987;24(suppl 1):170-1.
9 Flynn BJ. The quality assessment of blood glucose assays outside the laboratory-one year's experience. Ann Clin Biochem 1987;24(suppl 1):172-3.

10 Jones KW, Rady A, Holloran SP, Marks V. A system to improve the standard of bedside blood glucose measurements-its introduction and management. Ann Clin Biochem 1987;24(suppl 1):174-5.

11 Advisory Committee on Assessment of Laboratory Standards. United Kingdom external quality assessment schemes annual report 1987. London: DHSS, 1987.

12 Bullock DG, Broughton PMG. Cholesterol assays in primary care. Horizons 1988;2:700.

\section{Good clinical practice: a way to better drugs}

\section{Rules for clinical drug research that offer a prospect of better trials}

When drug regulatory authorities use the term "good clinical practice" clinicians may fear more bureaucratic constraints. No such assault is intended. Good clinical practice signifies a set of rules for performing standards and helping to encourage cross national acceptance of data from trials for regulation. The need for standards for performing clinical trials has grown as clinical evaluation of drugs has become more complicated. Poorly performed trials are still carried out and presented to regulatory agencies in support of new drug applications. The pharmaceutical industry, which sponsors most new drug trials, has therefore issued various good practice guidelines, ${ }^{1}$ and some national drug agencies-for example, in France, Japan, and the United States - have done the same. Over a decade ago the Food and Drug Administration worked out a large complex of regulatory requirements for clinical testing of investigational drugs, ${ }^{2}$ and the European Community is about to publish general recommendations on the conduct of clinical trials. ${ }^{3}$ Both the European Community and the Nordic Council of Medicines are presently drafting guidelines on good clinical practice.

Progress in the methods of trials and the general acceptance of ethical responsibility ${ }^{4}$ have stimulated this development, but just as important are political and commercial factors. Thus public and political concerns over widely published examples of research fraud, accidents during trials, and questionable ethics may be overdramatised but are not entirely unwarranted. Furthermore, to exploit the huge markets for drugs in the European Community, United States, and Japan pharmaceutical companies require that data from trials in one country are accepted in others. The member states must therefore also harmonise their own regulations. The good clinical practice guidelines being drafted by the European Community's committee on proprietary medicinal products and due to be published in early 1990 are a part of this initiative.

What does a good clinical practice guide contain? The likely construction of the European Community document may give some idea. It will include $(a)$ a detailed glossary explaining all the terms used in the document to avoid misunderstandings; (b) instructions protecting subjects taking part in the trial, in line with the Declaration of Helsinki, covering both ethics committees and informed consent; $(c)$ requirements for "standard operating procedures" explaining in detail the responsibilities of the sponsor (usually a pharmaceutical company), the investigator (the clinically responsible doctor), and the monitor (the sponsor's trial supervisor) before, during, and after the trial; $(d)$ instructions for drawing up protocols, reporting to the authorities - for example, adverse events - data handling and archiving, and statistics, etc; and (e) requirements for auditing, data verification, and quality control. The guidelines serve as a checklist to ensure that all those taking part in clinical drug research know exactly what is required of them. Those concerned should carefully adhere to the standards and procedures if they want the data produced to be used in applications for marketing authorisations. In this way dependable and verifiable data of the highest scientific and ethical quality may be generated. Although good clinical practice guidelines are primarily directed towards trials initiated by the pharmaceutical industry, their impact on the conduct of trials in general should not be underestimated.

The document now being drafted will not have the force of law when published, but it will carry considerable implications for those conducting clinical trials in Europe. Perhaps most important is the fact that investigators will be controlled and trials monitored to an extent that only few have experienced. In fact inspectors for the Food and Drug Administration have long visited investigators and sponsors in Europe as well as in the United States, and the French regulatory authority has already started doing the same. Such operations may be contrary to the traditions of European research, but verification of data should not be confused with interference with the free practice of medicine. Nevertheless, if a study is not performed in accordance with good clinical practice or the data cannot be verified then the study will not be accepted as part of a regulatory submission. As the demand for good clinical practice is essentially a demand for quality it should increase investigators' carefulness and prevent bungling and fraud. In turn, this may affect positively the practice of medicine in general and of drug treatment in particular.

Will the good clinical practice requirements help us to obtain better treatments? They probably will, but on two conditions: the trial regulations should not interfere unduly 
with the doctor-patient relationship, and progress must not be made at the expense of the integrity and welfare of existing patients. The standards must strike the right balance between optimal clinical research and careful clinical work. If they succeed they will benefit trial subjects, investigators, sponsors, regulators-and future patients.

Professor of Clinical Pharmacology,

EIGILL F HVIDBERG

University Hospital,

DK-2100 Copenhagen,

Denmark

\footnotetext{
1 Association of the British Pharmaceutical Industry. Guidelines on good clinical research practice. London: ABPI, 1988.

2 Kessler DA. The regulation of investigational drugs. N Engl f Med 1989;320:281-8.

3 Committee on Proprietary Medicinal Products, EEC. Recommended basis for the conduct of clinical trials of medicinal products in the European Community. Brussels: EEC (in press). (Document III/411/87.

4 Herxheimer A. The rights of the patient in clinical research. Lancet 1988;ii:1128-30.
}

\section{Epilepsy in women of childbearing age}

\section{If anticonvulsants cannot be avoided use carbamazepine}

Mothers who have epilepsy inevitably worry about the effect of the disease on their unborn babies. Questions about the impact of seizures on maternal and fetal health arise long before pregnancy occurs, and there is an increasing awareness of the teratogenic effect of anticonvulsant drugs. There is a genuine dilemma between controlling seizures and protecting the fetus from unnecessary exposure to anticonvulsant drugs. ${ }^{1}$ Unfortunately, some women are not told about the risk to the fetus and are not offered prenatal diagnosis. ${ }^{2}$

About one in 200 pregnancies is in a woman with epilepsy. ${ }^{3}$ Received wisdom suggests that pregnancy causes an increase in the fits, ${ }^{45}$ but this increase is largely caused by women not taking their drugs, losing sleep, and being given inadequate treatment. ${ }^{6}$ The pregnancy itself may have little influence on the pattern of attacks, and in a recent study there was no difference in the frequency of seizures before and during pregnancy. ${ }^{7}$ In general, women whose epilepsy is well controlled have few problems from their disease in pregnancy, and seizures increase in those whose attacks are poorly controlled at other times. In these circumstances generalised seizures are more hazardous than minor attacks: stillbirths have been recorded after a single generalised convulsion, ${ }^{8}$ and in a series of mothers with status epilepticus nine mothers and 14 infants died. ${ }^{9}$ Most of the complications of pregnancy are increased when the epilepsy is poorly controlled. ${ }^{910}$

Plasma concentrations of anticonvulsant drugs decrease during pregnancy. This does not commonly cause an increase in seizures, but when attacks do increase the plasma concentrations of the drugs are usually low. ${ }^{7}$ Reduction in blood concentration of anticonvulsant drugs may result from poor compliance ${ }^{6}$ increased metabolism of the drugs by hepatic enzymes, ${ }^{11}$ and a progressive reduction in albumin concentration, which may be associated with increased clearance of the unbound drug. ${ }^{12}$

Many different congenital malformations have been reported in children of epileptic mothers, and all anticonvulsant drugs have been incriminated as possible causes of the malformations. The most common abnormalities are orofacial clefts and congenital heart disease. ${ }^{13}$ Seventy abnormalities occur in every 1000 births to epileptic mothers, 2.4 times the rate in the general population. Abnormalities are more likely if anticonvulsant drugs are prescribed, ${ }^{13}$ if high concentrations of them are used, ${ }^{14}$ and if more than one is used. ${ }^{15}$ The first indication of a specific teratogenic effect resulting from anticonvulsant treatment was in 1982, when it was reported that nine out of 72 infants with neural tube defects in the Rhône Alps region of France had been exposed to valproic acid. ${ }^{16} \mathrm{~A}$ subsequent review of 2111 pregnancies showed a $1 \%$ risk of neural tube defects in infants exposed to valproic acid in utero ${ }^{17}-20$ times the rate in the general population.

Oakeshott and Hunt have recently reported three cases of spina bifida in infants born to women taking sodium valproate, none of whom were aware of the risk and none of whom were offered prenatal diagnosis. ${ }^{2}$ Their report emphasised the need for adequate counselling of pregnant women about the risks of anticonvulsant drugs, but of equal importance are the original choice of drug for girls with epilepsy, avoidance of polypharmacy, and regular review of the need for drug treatment. Although no anticonvulsant drug is free of risk, it seems prudent to avoid prescribing sodium valproate to girls unless there are specific indications such as generalised epilepsy with a combination of petit mal and major seizures. Petit mal alone is seldom a problem by the time pregnancy occurs, and thus even in the generalised epilepsies regular review is needed of the specific need for valproate.

The present consensus is that carbamazepine alone should be the first choice for a girl who requires an anticonvulsant drug. The need for continued treatment should then be reviewed after two years' remission. The results of the Medical Research Council's anticonvulsant withdrawal trial should provide more accurate information on relapse rates in the various groups, but in general any young woman free of seizures for two years should be offered the choice of withdrawing from anticonvulsant treatment.

There is much scope for improving the management of epilepsy in women of childbearing age. The greatest needs are better education of the women and their doctors and the recognition that in this particular group long term planning and good communication among the various caring agencies are of the utmost importance.

MICHAEL SAUNDERS

Consultant Neurologist,

Middlesbrough General Hospital,

Middlesbrough T\$5 5AZ

1 Yerby SM. Problems and management of the pregnant woman with epilepsy. Epilepsia 1987;28: $529-36$.

Oakeshott P, Hunt GM. Valproate and spina bifida. Br Med f 1989;298:1300-1.

3 Kalter H, Warkany J. Congenital malformations. N Engl F Med 1983;308:491-7.

4 Knight AH, Rhind EG. Epilepsy and pregnancy: a study of 153 pregnancies in 59 patients. Epilepsia 1975;16:99-110.

5 Philbert A, Dam M. The epileptic mother and her child. Epilepsia 1982;23:85-99.

6 Schmidt D, Conyen R, Avanzini G, et al. Change of seizure frequency in pregnant epileptic women. I Neurol Neurosurg Psychiatry 1983;46:751-5.

Gjerde IO, Strandjord RE, Ulstein $M$. The course of epilepsy during pregnancy: a study of 78 cases. Acta Neurol Scand 1988;78:198-205.

8 Higgins TA, Commerford JB. Epilepsy in pregnancy. Journal of the Irish Medical Association 1974;67:317-29.

9 Teramo K, Hiilesmaa VK. Pregnancy and foetal complications in epileptic pregnancies: a review of the literature. In: Janz D, Bossi L, Dam M, et al, eds. Epilepsy, pregnancy and the child. New York: Raven Press, 1982:53-9.

10 Yerby MS, Koepsell T, Daling J. Pregnancy complications and outcomes in a cohort of women with epilepsy. Epilepsia 1985;26:631-5.

$11 \mathrm{Nau} \mathrm{H}, \mathrm{Kunhz} \mathrm{H}$, Egger HJ, et al. Anticonvulsants during pregnancy and lactation: transplacental, maternal and neonatal pharmacokinetics. Clin Pharmacokinet 1981;7:508-43.

12 Yearby MS, Friel PN, Miller DQ. Carbamazepine protein binding and disposition in pregnancy. Ther Drug Monit 1985;7:269-73.

Ther Drug Monit 1985;7:269-73.
3 Fedrick J. Epilepsy and pregnancy: a report from the Oxford Record Linkage Study. Br Med $\mathcal{F}$ 1973;ii:442-8.

14 Danski LV, Andermann E, Andermann F, et al. Maternal epilepsy and congenital malformations: correlation with maternal anticonvulsant levels during pregnancy. In: Janz D, Bossi L, Dam M et al, eds. Epilepsy, pregnancy and the child. New York: Raven Press, 1982:251-8.

15 Lindhout D, Hoppener RJ, Meinardi $\mathrm{H}$. Teratogenicity of antiepileptic drug combinations with special emphasis on epoxidation of carbamazepine. Epilepsia 1984;25:77-83.

16 Valproic acid and spina bifida, preliminary report. MMWR 1982;31:565-6.

17 Lindhout D, Schmidt D. In-utero exposure to valproate and neural tube defects. Lance 1986;i:1392-3. 